\title{
Development of Marbling in Beef Cattle Can Be Modulated through the Control of Adipogenic Activity
}

\author{
Theresia Galuh Wandita \\ Department of Animal Life and Environment Science \\ Anseong-si, Gyeonggi-do, South Korea \\ Najuma Joshi \\ Department of Animal Life and Environment Science \\ Anseong-si, Gyeonggi-do, South Korea
}

\author{
Delgerzul Bataar \\ Department of Animal Life and Environment Science \\ Anseong-si, Gyeonggi-do, South Korea \\ Seong Gu Hwang \\ Department of Animal Life and Environment Science \\ Anseong-si, Gyeonggi-do, South Korea \\ sghwang@hknu.ac.kr
}

\begin{abstract}
Increase in marbling is one of the essential factors for enhancement of tenderness in beef. Adipogenesis; the main contributor in marbling, consists of two stages: preadipocyte determination and adipocyte differentiation. Preadipocyte determination occurs even from growing stage, while adipocyte differentiation occurs in fattening stage of beef cattle. The effectiveness of nutritional and hormonal challenges to enhance adipogenesis is important to design a least-cost production. The influence of nutrition and hormone was found on adipogenesis in stromal vascular cells isolated from native Hanwoo beef cattle adipose tissue. In this study, high level of acetate, which is the most predominant volatile fatty acid produced in the rumen, was effectively increased preadipocyte determination in stromal vascular cells, while high level of propionate was observed to effectively support adipocyte differentiation. On the other hand, a high level of testosterone was observed to decrease adipogenesis. This study suggests that acetate is preferred in the growing stage and propionate in the fattening stage. Furthermore, low concentration of testosterone is favorable for the preadipocyte determination of progenitor cells as well as adipocyte differentiation.

Keywords: acetate; growth hormone; intramuscular fat;
\end{abstract} propionate; testosterone

\section{INTRODUCTION}

Consumers demand for tender, flavorful and juicy beef as the traits are very important for its palatability. Development of marbling is essential for increasing the tenderness in beef. Marbling is the visible intramuscular fat within a cross-section of meat, and is positively correlated with beef juiciness, perceived tenderness, and palatability [1] [2] . Korea has increased the intramuscular fat deposition of native Hanwoo beef cattle by more than $30 \%$, over the course of more than two decades [3].

The formation and growth of adipose tissue involves both hyperplasia (increased cell numbers) and hypertrophy (increased cell size). Adipogenesis is the process of proliferation of preadipocytes and their differentiation into mature adipocytes. Preadipocytes and adipocytes are a major factor for adipose tissue expansion, as well as being the main contributors to intramuscular fat deposition. Hypertrophy of adipocytes occurs as they accumulate triglycerides created through lipogenesis [4][5][6][7]. Because of the importance of adipogenesis, there has been considerable research carried out on different approaches to enhance intramuscular fat deposition.

Zfp423 (Zinc finger protein 423), which is abundantly found in preadipose adipoblasts, has been identified as a critical regulator of the preadipocyte determination in the primary cell cultures [8][9][10]. The Zfp423 expression is augmented in numerous preadipocyte cell lines when compared to fibroblast cell lines [11]. Zfp423 regulates preadipocyte levels of PPAR $\gamma$, and is required for proper white and brown adipocyte differentiation in vitro and in vivo [12][10]. In addition, other regulators of the PPAR $\gamma$ expression, such as $\mathrm{C} / \mathrm{EBP} \alpha$, may be expressed to compensate for loss of Zfp423, in order to maintain adipocyte transcription factor expressions. By contrast, in mature white adipocytes, Zfp423 is able to suppress the thermogenic gene program associated with beige/brown adipocytes. It regulates the initial formation of white adipocytes and later plays a role in maintaining energy storage.

Volatile fatty acids (VFAs), a primary source of energy for ruminants, are produced from microbial fermentation of feed carbohydrates in the rumen [13][14]. Acetate is the most common VFA produced in the rumen, and high levels of acetate maintain stable fermentation in the rumen, and stabilize its $\mathrm{pH}$.

Excess concentrate diet in ration increases propionate production, decreases rumen $\mathrm{pH}$, reduces feed intake and reduces microbial reproduction [15][16]. High levels of propionate in the rumen might, in turn, lead to depressed fiber digestion and acidosis. Moreover, glucose contributes a greater proportion of the carbon used for fatty acid biosynthesis in intramuscular sites, rather than in subcutaneous adipose tissue, while acetate is thought to contribute to the development of committed preadipocytes [17][18].

Because acetate and propionate are the most common VFAs, their role in cattle becomes an interesting issue in relation to intramuscular fat deposition in adipose tissue. Either acetate or propionate is thought to be required by the mesenchymal stem cells to develop into preadipocytes and adipocytes, although precise understanding of the function and performance of acetate and propionate in beef cattle adipose tissue is still lacking. 
Besides nutritional factors, hormone is also suspected to contribute in the deposition of marbling in beef cattle. The palatability of late-castrated beef is lower than perfect timingcastrated beef [19]. Castrated males had greater marbling scores than intact males [20]. This may be attributed to $30 \%$ less intramuscular fat levels in bulls than steers [21]. Castration practices are reported to reduce blood testosterone level [22]. Testosterone, a male reproductive steroid hormone, has been observed to suppress adipogenesis [23][24]. [25] reported that testosterone deficiency may reduce the buffering capability for glucose uptake and utilization in muscle and subcutaneous adipose tissue and it would lead to lipid accumulation in liver and aortic root. Low growth hormone level has been reported to be associated with castration [26]. Growth hormone is peptides hormone which is secreted by somatotropic cells in the pituitary gland. Increased total fat mass and visceral fat is associated with the absence of growth hormone in the body. On the other hand, it decreases muscle mass [27]. Additionally, growth hormone is also known to promote muscle development while stimulating lipolysis in adipocytes [28]. However, the effect of testosterone and growth hormone in marbling deposition is still poorly understood.

This study aimed to investigate and clarify the effect of different levels of acetate and propionate on the proliferation and differentiation of stromal vascular cells (SVC) isolated from Hanwoo Korean beef cattle intramuscular fat. Besides, the effect of different levels of testosterone and growth hormone was also investigated to explore their effects in marbling of beef cattle.

\section{METHODS}

\section{a. Enzyme-linked immunosorbent assay (ELISA)}

Blood serum was collected from steers castrated at 4-5 months, 7-8 months, non-castrated cattle, and heifer. All the animals were around 8 months old during the sample collection. All animal used for the research were Korean native Hanwoo beef cattle. Total content of testosterone and growth hormone were analyzed using bovine ELISA kit assay (Cusabio Biotech, Co., Ltd., Wuhan, China) according to the manufacturer's instruction.

\section{b. Stromal Vascular Cell isolation}

SVC was isolated from muscle tissue (Longissimus dorsi) of 15 month old castrated Hanwoo beef cattle. Muscles were collected directly from a slaughterhouse in Anseong (Gyeonggi Province, South Korea). They were placed in a sterile ice-cold Phosphate Buffer Saline (PBS), which contained $1 \mathrm{ml} / \mathrm{L}$ Amphotericin B and $4 \mathrm{ml} / \mathrm{L}$ gentamycin, while in transit to the laboratory, where adipose tissue was resected and put in isolation media $(10 \%$ BCS-DMEM containing $1 \mathrm{mg} / \mathrm{ml}$ collagenase type 1 and $0.4 \mathrm{~g} / \mathrm{ml}$ bovine serum albumin).

Digestion was performed for 50 minutes, at $37^{\circ} \mathrm{C}$, in an agitated water bath, operating at a speed of 60 cycles per minute. After digestion, $5 \mathrm{ml}$ of BCS-DMEM was added to the isolating media to stop the digestion, the suspension was filtered using a $100 \mu \mathrm{m}$ nylon cell strainer, and was then centrifuged at $1000 \mathrm{rpm}$ for $10 \mathrm{~min}$, at room temperature. The filtrate was washed in $10 \mathrm{ml}$ of RBC lysis buffer and centrifuged at $1000 \mathrm{rpm}$ for $10 \mathrm{~min}$, at room temperature. The cells were then re-suspended in $10 \mathrm{ml}$ of growing media $(10 \%$ BCS-DMEM containing 1\% penicillin-streptomycin). Cells were incubated at $37{ }^{\circ} \mathrm{C}$ under $5 \% \mathrm{CO}_{2}$ until fully attached to the plate.

\section{c. SVC culture and treatments}

SVC were cultured in growing media and incubated at 37 ${ }^{\circ} \mathrm{C}$ under $5 \% \mathrm{CO}_{2}$. Every 2 days after isolation, the growing media was renewed, to maintain cell cultures. As the cells commenced differentiation, the SVC was cultured in $10 \%$ FBS-DMEM supplemented with 1\% Penicillin-streptomycin. In order to accelerate cell differentiation, on the day of differentiation, cells were induced with $10 \mu \mathrm{l}$ each of isobuthylmethylxanthine (IBMX), dexamethasone (DEX), insulin (INS) and rosiglitazone. Every 2 days, the media was replaced with a fresh FBS-DMEM, and induced with only insulin and rosiglitazone.

As the SVC proliferated and continued differentiation, they were treated with different concentrations of sodium acetate trihydrate $98.5 \%$ and sodium propionate $99.0 \%$ $(0.125,0.25,0.5$, and $1 \mathrm{mMol})$. In order to study the hormonal effect, cells were treated with high and low level of testosterone $(0.2$ and $20 \mathrm{ng} / \mathrm{ml})$ and growth hormone (5 and $15 \mathrm{ng} / \mathrm{ml})$.

\section{d. Preadipocyte proliferation}

Cells were seeded in 6-well plates, at a density of $1 \times 10^{8}$ cells/well, and treated with different concentrations of acetate and propionate. Cells were incubated, and then harvested at 72 hours. Meanwhile, for testosterone study cells were harvested on Day-5. Total RNA was extracted from each plate using RNAiso Plus, and then cDNA was synthesized from the RNA sample using a Thermo fisher PCR set, containing 10 $\mathrm{mM}$ dNTP Mix, $0.2 \mu \mathrm{g} / \mu 1$ random hexamer primer, $40 \mathrm{U} / \mu \mathrm{l}$ RiboLock RNAse inhibitor, $200 \mathrm{U} / \mu 1$ RevertAid Reverse Transriptase, and $5 \times$ reaction buffer. Reverse-Transcriptase Polymerase Chain Reaction was performed to identify the expression of Zfp 423 and Pref-1. The oligonucleotide primers used in this study were shown in Table 1.

\section{e. Triglycerides analysis}

Triglyceride analysis was quantified by elution of OilRed-O stained with isopropanol, and the optical density was measured at $490 \mathrm{~nm}$.

\section{f. Reverse-Transcriptase Polymerase Chain Reaction}

Fully differentiated SVC were harvested using RNAiso Plus, according to the manufacturer's instructions. Then cDNA was synthesized from the RNA sample, using a Thermo fisher PCR set containing $10 \mathrm{mM}$ dNTP Mix, 0.2 $\mu \mathrm{g} / \mu \mathrm{l}$ random hexamer primer, $40 \mathrm{U} / \mu \mathrm{l}$ RiboLock RNAse inhibitor, $200 \mathrm{U} / \mu 1$ RevertAid Reverse Transriptase, and 5× reaction buffer. A maxime RT Premix Kit was used to mix 1 $\mu \mathrm{g}$ of cDNA and $20 \mu \mathrm{l}$ of primer marker. The cDNA was then incubated in a thermocycler for an initial denaturation cycle, at $95{ }^{\circ} \mathrm{C}$ for $5 \mathrm{~min}$, followed by 30 amplification cycles of 40 sec at $95{ }^{\circ} \mathrm{C}$, annealing for $40 \mathrm{sec}$ at $50-60{ }^{\circ} \mathrm{C}$, and final extension at $72{ }^{\circ} \mathrm{C}$ for $1 \mathrm{~min}$. The oligonucleotide primers used in this study were shown in Table 1.

\section{g. Real-Time PCR}

cDNA was synthesized from the RNA sample, and SYBR Green PCR Master Mix was used for quantification of target mRNA by real-time PCR. Quantification of target mRNA was performed using the standard curve method according to the 
manufacturers protocol (PE Applied Biosystems). The amplification steps included $50{ }^{\circ} \mathrm{C}$ for $2 \mathrm{~min}, 95^{\circ} \mathrm{C}$ for $10 \mathrm{~min}$ and 40 cycles of $95^{\circ} \mathrm{C}$ for $15 \mathrm{~s}$ and $60^{\circ} \mathrm{C}$ for $1 \mathrm{~min}$. Duplicate values of the same sample were almost equivalent. The quantification was also normalized by $\beta$-actin expression. The oligonucleotide primers used in this study were shown in Table 1.

\section{h. Western Blotting}

Protein was extracted from fully differentiated SVC by adding $200 \mu \mathrm{l}$ protein extraction solution. The lysates were purified by centrifugation at $15000 \mathrm{rpm}$ for $14 \mathrm{~min}$ at $4{ }^{\circ} \mathrm{C}$, and protein concentrations were then determined using Bradford assay. To prepare the electrophoresis gel, $35 \mu \mathrm{g}$ of the protein sample was separated by vertical electrophoresis (SDS-PAGE), and transferred to nitrocellulose transfer membranes. The membranes were blocked with 5\% skimmed milk, and hybridized with the following primary Abcam ${ }^{\mathrm{TM}}$ antibodies: mouse monoclonal anti-beta actin (ab6276), rabbit polyclonal anti-PPAR gamma (ab45036), rabbit polyclonal anti-FABP4 (ab85875), rabbit polyclonal anti-CEBP alpha (ab140479), and mouse monoclonal anti-SREBP1 from Santa Cruz Biotechnology (sc-365513). The target protein was exposed and detected on radiographic film, after membrane incubation with horseradish peroxidase, to enhance the chemiluminescence.

\section{i. Statistical analysis}

All the quantitative data were shown as the mean \pm SD. Differences between groups were analyzed using one-way ANOVA, followed by Duncan's Multiple Range Test (DMRT). The level of statistical significance was set at $\mathrm{P}<$ 0.05. The statistical software package SPSS 15.0 (SPSS Inc., Chicago, Ill., USA) was used for the analysis.

\section{RESULTS AND DISCUSSION}

\section{Nutritional effects}

To identify the existence of preadipocytes, gene expressions for Zfp423 and Pref-1, transcription factors that are critical regulators for determining committed preadipocytes, were performed. As shown in Figure 1A, representative mRNA bands for Zfp423 and Pref-1 were significantly expressed after treatment for $72 \mathrm{~h}$ with different concentrations of acetate. The result suggested that acetate promoted preadipocyte determination in SVC isolated from Hanwoo beef cattle.

Interestingly, representative mRNA bands for Zfp423 and Pref-1 were not significantly expressed in the propionatetreated group (Figure 1B), which showed a similar expression for all concentrations; in other words, this study has shown that committed preadipocyte determination in bovine SVC was not affected by increasing the concentration of propionate. The result suggested that propionate did not promote preadipocyte determination in SVC isolated from Hanwoo beef cattle.

Zfp423 may provide a molecular target for enhanced intramuscular adipogenesis and marbling in beef cattle [9]. Pref-1 activated signaling through ERK/MAPK pathways, to promote cell proliferation and inhibit adipocyte differentiation [29]. Acetate promoted both proliferation and determination of preadipocytes in SVC isolated from rat, through STAT3 and MAPK signaling pathways. Acetate activated leptin secretion, and increased the phosphorylation of p42 and p44 isoforms, to produce preadipocytes cells [30]. [31] mentioned that propionate, which was converted into glucose in the liver, supported the proliferation of different kinds of cells. Glucose is an essential nutrient which is very useful for cell growth. Propionate promoted proliferation of SVC, but it did not enhance the determination of preadipocytes. Preadipocytes are fat cell precursors and are an important cell type for adipocyte development [32].

In this study, the highest lipid accumulation was shown by the addition of $1.0 \mathrm{mMol}$ acetate, as shown by the increased number of triglycerides in Figure 2A. Unlike the acetate effects, propionate showed an excellent result for total triglycerides. As shown in Figure 2B, accumulated lipid in bovine SVC, after treatment with different concentrations of propionate increased along with the increased concentration of propionate.

Activation of acetate to acetyl-CoA promoted the accumulation of lipid or triglyceride deposition in the adipose tissue. In ruminants, acetate carbons come into play twice, once as the source of acetyl-CoA, to enter the malonyl-CoA pathways, and once as the source of malonyl-CoA that adds the two carbons to each cycle of the fatty acid synthetase. Acetate was preferred as a substrate for fat synthesis in subcutaneous adipocyte, while it was still possible that acetate was used for fat synthesis in intramuscular adipocyte. Acetyl CoA, which activated from acetate, was used as one precursor in fatty acid synthesis [14]. [33] concluded that acetate still promoted cells hyperplasia, even in the differentiation stages. Based on that experiment, it has been concluded here that maximal differentiation was not attained in differentiated bovine SVC because acetate was also used up supporting cell proliferation.

Preadipocyte differentiation into mature adipocytes can also be identified from their molecular activity, such as the gene and protein expressions. In this study, further experiments were conducted to evaluate expressions of adipogenic-related markers, such as PPAR $\gamma, \mathrm{C} / \mathrm{EBP} \alpha$, SREBP-1c, and FABP4, in both genes and proteins, through Reverse Transcriptase-Polymerase Chain Reaction and Western blot experiments, respectively.

As shown in Figure 4, genes and protein expressions of differentiated SVC, after treatment with different concentrations of acetate, favored lipid accumulation. All adipogenic transcription factors for genes and protein expression showed that increasing the concentration of acetate up to $1.0 \mathrm{mMol}$ also increased the PPAR $\gamma, \mathrm{C} / \mathrm{EBP} \alpha$, SREBP-1c, and FABP4 expressions; at higher concentrations, they decreased. This suggested that concentration of acetate up to $1.0 \mathrm{mMol}$ was effective for the differentiation of bovine SVC.

As shown in Figure 5, as expected, genes and protein expressions of differentiated SVC, after treatment with propionate, supported lipid accumulation data. All adipogenic transcription factors for genes and protein expressions showed that increasing the concentration of propionate up to $1.0 \mathrm{mMol}$, increased the expressions of PPAR $\gamma, \mathrm{C} / \mathrm{EBP} \alpha$, SREBP-1c, and FABP4. The results suggested that both genes and protein expressions were significantly influenced by different concentrations of 
propionate, illustrating very well a significant effect of propionate on bovine SVC, compared with acetate.

About $90 \%$ of propionate is converted into glucose in the liver. Then, the glucose is accessible in the blood. Insulin plays an important role in glucose metabolism regulation by stimulating the GLUT-4 expression, which in turn mediates glucose uptake in adipose tissue. Glucose was seen as an important source of ATP in the adipocytes, and was used for triglyceride synthesis [34]. Besides that, GLUT-4 also led to adipocyte hyperplasia via enhanced fatty acid esterification [35].

\section{Hormonal effects}

Testosterone and growth hormone level in Hanwoo beef cattle's blood in different age and sex is shown in Table 2. Similarly, the highest testosterone and growth hormone level was observed in steers castrated at 7-8 month old, while the lowest was in castrated at 4-5 month old. Their hormones levels were then used for further study.

As shown in Figure 6, testosterone suppressed the expression of committed preadipocyte determination, such as Zfp423 and Pref-1. Committed preadipocyte determination was affected by high levels of testosterone $(20 \mathrm{ng} / \mathrm{ml})$. Testosterone inhibited preadipocyte determination through AR-mediated pathway which is known to regulate myogenic progenitor cells determination or brown adipogenic lineage [36] [37]. Zfp423 is an important expression for committed preadipocytes determination in white adipose tissue [12].

To evaluate the effects of testosterone and growth hormone on preadipocyte differentiation into mature adipocyte, total triglyceride and molecular activity of differentiated SVC were identified. The expression of early adipogenic marker genes was conducted, such as PPAR $\gamma$ and $\mathrm{C} / \mathrm{EBP} \alpha$, through Real-Time PCR.

Total triglyceride decreased along with increase in the high levels of testosterone and growth hormone (Figure 7). Similarly, the expression of PPAR $\gamma$ and $\mathrm{C} / \mathrm{EBP} \alpha$, a key inducer of terminal adipocyte commitment [38], was also decreased in high levels of testosterone and growth hormone as shown in Figure 8. Those results indicated that high levels of testosterone and growth hormone inhibited the differentiation of SVC isolated from Hanwoo beef cattle. Low levels of testosterone and growth hormone was favorable to promote preadipocyte differentiation into mature adipocyte.

Growth hormone plays a major role in growth and development of steers by promoting lipolysis of adipocyte and gluconeogenesis in muscle and bone growth [39]. [40] mentioned that growth hormone is 3 -fold greater in latecastrated cattle than early-castrated steer. Furthermore, it prevents lipid accumulation in adipocytes by encouraging lipolysis activity of HSL (Hormone-sensitive lipase) [41].

\section{CONCLUSION}

Acetate and propionate, which are produced in the rumen by microorganism metabolism of carbohydrate, are important nutrients, which contribute to increased intramuscular fat, or marbling, in beef cattle. Acetate is mostly produced from high quality roughage, while propionate is produced from feed concentrates. Acetate is preferred in the proliferation stage, which is the growing stage of beef cattle, because it effectively promotes preadipocyte determination from mesenchymal stem cells. Propionate is preferred at the differentiation stage, which is the fattening stage of beef cattle, because it significantly enhances preadipocyte differentiation into mature adipocytes.

Based on the results, it can be inferred that low concentration of testosterone is favorable for the preadipocyte determination of progenitor cells as well as adipocyte differentiation. Thus, to favor the adipogenic determination of progenitor cells, the testosterone should be maintained in low level which can be obtained by castrating the beef cattles in early age (4-5 months) because if the animals are castrated after 7-8 months, it will prolong exposure of progenitor cells to high testosterone level which inhibits preadipocyte determination of the cells, and ultimately affects intramuscular fat deposition in fattening phase.

Further studies need to be conducted to clarify the signaling pathways associated with their effects of on SVC proliferation and differentiation. Research on living animals must also be conducted, to increase the validity of this experiment.

\section{ACKNOWLEDGMENTS}

This work was financially supported by grants from Korea Institute of Science and Technology Evaluation and Planning (Project No. 012687-03).

\section{REFERENCE}

[1] Wheeler, T. L., Cundiff, L. V., and Koch, R. M. Effect of marbling degree on beef palatability in Bos taurus and Bos indicus cattle. J Anim Sci 72, no. 12 (1994): 3145-3151

[2] Albrecht, E., Gotoh, T., Ebara, F., Xu, J. X., Viergutz, T., Nürnberg, G., Maak, S., and Wegner, J.. Cellular conditions for intramuscular fat deposition in Japanese Black and Holstein steers. Meat Sci 89, no. 1 (2011): 13-20.

[3] Smith, S. B., and Johnson, B. J. Marbling: management of cattle to maximize the deposition of intramuscular adipose tissue. J Anim Sci 94, no 5 (2016): 382

[4] Hausman, D. B., DiGirolamo, M., Bartness, T. J., Hausman, G. J., and Martin, R. J. The biology of white adipocyte proliferation. Obes Rev 2 , no. 4 (2001): 239-254.

[5] Fernyhough, M. E., Okine, E., Hausman, G. Vierck, J. L., and Dodson, M. V. PPAR $\gamma$ and GLUT-4 expression as developmental regulators/markers for preadipocyte differentiation into an adipocyte. Domest Anim Endocrinol 33, no. 4 (2007): 367-378.

[6] Brooks, M. A., Choi, C. W., Lunt, D. K., Miller, R. K., Choi, C. B., and Smith, S. B.. CASE STUDY: Carcass and meat characteristics and M. longissimus thoracis histology of beef from calf-fed and yearling-fed Angus steers. The Professional Animal Scientist 27, no. 4 (2011): 385 393.

[7] Lee, S. H., Gondro, C., Werf, J. V. D., Kim, N. K., Lim, D. J., Park, E. W., Oh, S. J., Gibson, J. P., and Thompson, J. M. Use of a bovine genome array to identify new biological pathways for beef marbling in Hanwoo (Korean Cattle). BMC Genomics 11, no. 1 (2010): 623.

[8] Gupta, R. K., Arany, Z., Seale, P., Mepani, R. J., Ye, L., Conroe, H. M., Roby, Y. A., Kulaga, H., Reed, R. R., and Spiegelman, B. M. Transcriptional control of preadipocyte determination by Zfp423. Nature 464, no. 7288 (2010): 619.

[9] Huang, Y., Das, A. K., Yang, Q. Y., Zhu, M. J., and Du, M. Zfp423 promotes adipogenic differentiation of bovine stromal vascular cells. PloS one 7, no. 10 (2012): e47496. 
[10] Moseti, D., Regassa, A., and Kim, W. K. Molecular regulation of adipogenesis and potential anti-adipogenic bioactive molecules. Int $J$ Mol Sci 17, no. 1 (2016): 124.

[11] Vishvanath, L., MacPherson, K. A., Hepler, K., Wang, Q. A., Shao, M., Spurgin, S. B., Wang, M. Y., Kusminski, C. M., Morley, T. S., and Gupta, R. K. Pdgfr $\beta+$ mural preadipocytes contribute to adipocyte hyperplasia induced by high-fat-diet feeding and prolonged cold exposure in adult mice. Cell Metab 23, no. 2 (2016): 350-359.

[12] Shao, M., Ishibashi, J., Kusminski, C. M., Wang, Q. A., Hepler, C., Vishvanath, L., MacPherson, K. A., Spurgin, S. B., Sun, K., Holland, W. L., and Seale, P. Zfp423 maintains white adipocyte identity through suppression of the beige cell thermogenic gene program. Cell Metab 23, no. 6 (2016): 1167-1184.

[13] Wattiaux, M. A. Dairy Essentials Reproduction and Genetic Selection. Birth 42, no. 32 (1996): 25

[14]Hong, Y. H., Nishimura, Y., Hishikawa, D., Tsuzuki, H., Miyahara, H., Gotoh, C., Choi, K. C., Feng, D. D., Chen, C., Lee, H. G., and Katoh, K. Acetate and propionate short chain fatty acids stimulate adipogenesis via GPCR43. Endocrinology 146, no. 12 (2005): 5092-5099.

[15] Russell, J. B. The importance of $\mathrm{pH}$ in the regulation of ruminal acetate to propionate ratio and methane production in vitro. J Dairy Sci 81, no. 12 (1998): 3222-3230.

[16] Aschenbach, J.R., Bilk, S., Tadesse, G., Stumpff, F., and Gäbel, G. Bicarbonate-dependent and bicarbonate-independent mechanisms contribute to nondiffusive uptake of acetate in the ruminal epithelium of sheep. Am. J. Physiol Gastrointest Liver Physiol 296, no. 5 (2009): G1098-G1107.

[17] Hausman, G. J., Dodson, M. V., Ajuwon, K., Azain, M., Barnes, K. M., Guan, L. L., Jiang, Z., Poulos, S. P., Sainz, R. D., Smith, S., and Spurlock, M. Board-invited review: the biology and regulation of preadipocytes and adipocytes in meat animals. J Anim Sci 87, no. 4 (2009): 1218-1246.

[18] Nayananjalie, W. A. D., Wiles, T. R., Gerrard, D. E., McCann, M. A., and Hanigan, M. D. Acetate and glucose incorporation into subcutaneous, intramuscular, and visceral fat of finishing steers. J Anim Sci 93, no. 5 (2015): 2451-2459.

[19] Warnock, T. M., Thrift, T. A., Irsik, M., Hersom, M. J., Yelich, J. V., Maddock, T. D., Lamb G. C. \& Arthington, J. D. (2012). Effect of castration technique on beef calf performance, feed efficiency, and inflammatory response. J Anim Sci, 90 no. 7 (2012): 2345-2352.

[20]Gregory, K. E., \& Ford, J. J. Effects of Late Castration, Zeranol and Breed Group on Growth, Feed Efficiency and Carcass Characteristics of Late Maturing Bovine Males 1, 2. J Anim Sci 56, no. 4 (1983): 771-780.

[21] Purchas, R. W., Burnham, D. L., \& Morris, S. T. Effects of growth potential and growth path on tenderness of beef longissimus muscle from bulls and steers. J Anim Sci 80, no. 12 (2002): 3211-3221.

[22] Álvarez-Rodríguez, J., Albertí, P., Ripoll, G., Blasco, I., \& Sanz, A. Effect of castration at 10 months of age on growth physiology and behavior of male feral beef cattle. J Anim Sci 88, no. 7 (2017): 991-998.

[23] Chazenbalk, G., Irge, D., Shah, A., \& Dumesic, D. A. Testosterone inhibits subcutaneous abdominal adipogenesis during adipose stem cell differentiation to preadipocytes. Fertil Steril 96, no. 3 (2011): S114S115.

[24]Ren, X., Fu, X., Zhang, X., Chen, S., Huang, S., Yao, L., \& Liu, G. Testosterone regulates 3T3-L1 pre-adipocyte differentiation and epididymal fat accumulation in mice through modulating macrophage polarization. Biochem Pharmacol 140 (2017): 73-88.

[25]Kelly, D. M., Akhtar, S., Sellers, D. J., Muraleedharan, V., Channer, K. S., \& Jones, T. H. Testosterone differentially regulates targets of lipid and glucose metabolism in liver, muscle and adipose tissues of the testicular feminised mouse. Endocrine 54, no. 2 (2016): 504-515.

[26] Wang, J., Chen, J., Zhang, J., Gao, B., Bai, X., Lan, Y., Lin, P., Guo, H., Gao, Y. \& Xing, B. Castration-induced changes in the expression profiles and promoter methylation of the GHR gene in Huainan male pigs. J Anim Sci 88, no. 8 (2017): 1113-1119.

[27]Hull, K. L., \& Harvey, S. Growth hormone and reproduction: a review of endocrine and autocrine/paracrine interactions. Int J Endocrinol (2014).
[28] Chaves, V. E., Júnior, F. M., \& Bertolini, G. L. The metabolic effects of growth hormone in adipose tissue. Endocrine 44, no. 2 (2013): 293-302.

[29] Wang, Y., Zhao, L., Smas, C., and Sul, H. S. Pref-1 interacts with fibronectin to inhibit adipocyte differentiation. Mol Cell Biol 30, no. 14 (2010): 3480-3492.

[30] Machinal-Quelin, F., Dieudonne, M. N., Leneveu, M. C., Pecquery, R., and Giudicelli, Y. Proadipogenic effect of leptin on rat preadipocytes in vitro: activation of MAPK and STAT3 signaling pathways. Am J Physiol Cell Physiol 282, no. 4 (2002): C853-C863

[31] Wan, R., Du, J. P., Ren, L. P., and Meng, Q. X. Selective adipogenic effects of propionate on bovine intramuscular and subcutaneous preadipocytes. Meat Sci 82, no. 3 (2009): 372-378

[32]Florido, R, Tchkonia, T., and Kirkland, J. L. Aging and adipose tissue. In Handbook of the Biology of Aging (Seventh Edition), pp. 119-139. 2011

[33] Rutkowski, J. M., Stern, J. H., and Scherer, P. E. The cell biology of fat expansion. J Cell Biol 208, no. 5 (2015): 501-512.

[34] Frayn, N. K., and Humphreys, S. M.. Metabolic characteristics of human subcutaneous abdominal adipose tissueafter overnight fast. Am J Physiol Endocrinol Metab 302, no. 4 (2011): E468-E475.

[35]Herman, M. A., Peroni, O. D., Villoria, J., Schön, M. R., Abumrad, N. A., Blüher, M., Klein, S., and Kahn, B. B. A novel ChREBP isoform in adipose tissue regulates systemic glucose metabolism. Nature 484, no. 7394 (2012): 333

[36]Basualto-Alarcón, C., Jorquera, G., Altamirano, F., Jaimovich, E., \& Estrada, M. Testosterone signals through mTOR and androgen receptor to induce muscle hypertrophy. Med Sci Sports Exerc 45, no. 9 (2013): $1712-1720$

[37]Francetic, T., \& Li, Q. Skeletal myogenesis and Myf5 activation. Transcription 2, no. 3 (2011): 109-114

[38] Siersbæk, R., Nielsen, R., \& Mandrup, S. PPAR $\gamma$ in adipocyte differentiation and metabolism-Novel insights from genome-wide studies. FEBS letters 584, no. 15 (2010): 3242-3249.

[39] Burton, J. L., McBride, B. W., Block, E., Glimm, D. R., \& Kennelly, J. J. A review of bovine growth hormone. Can J Anim Sci 74, no. 2 (1994): 167-201.

[40] Skarda, J. Effect of bovine growth hormone on growth, organ weights, tissue composition and adipose tissue metabolism in young castrated male goats. Livest Prod Sci 3, no. 55 (1998): 215-225.

[41]Nielsen, T. S., Jessen, N., Jørgensen, J. O. L., Møller, N., \& Lund, S. Dissecting adipose tissue lipolysis: molecular regulation and implications for metabolic disease. J Mol Endocrinol, JME-13 (2014). 
Table 1 List of primers used in the PCR analysis to identify the nutritional and hormonal effects on differentiated SVC isolated from Hanwoo beef cattle adipose tissue

\begin{tabular}{lll}
\hline \hline \multirow{2}{*}{ Genes } & \multicolumn{1}{c}{ Forward } & \multicolumn{1}{c}{ Primers } \\
\cline { 2 - 3 } B-actin & 5'-CGC CAT GGA TGA TAT TGC-3' & 5'-AAG CGG CCT TGC ACA T-3' \\
Zfp423 & 5'-GGA TTC CTC CGT GAC AGC A-3' & 5'- TCG TCC TCA TTC CTC TCC TCT-3' \\
Pref-1 & 5'-CTC CCA GGC CAT CTG CTT C-3' & 5'-ACA TGT GGT TGT AGC GCA GA-3' \\
PPAR $\gamma$ & 5'-CAT CTT CCA GGG GTG TCA GT-3' & 5'-GGA TAT GAG GAC CCA TCC T-3' \\
C/EBP $\alpha$ & 5'-GCT GAC CAG TGA CAA TGA CC-3' & 5'-CTT GAC CAG GGA GCT CTC G-3' \\
FABP4 & 5'-AAG CTG CAC TTC TTT CTC ACC-3' & 5'-GAC CAC ACC CCC ATT CAA AC-3' \\
SREBP-1c & 5'-ACC GCT CTT CCA TCA ATG AC-3' & 5'-TTC AGC GAT TTG CTT TTG TG-3' \\
\hline
\end{tabular}

Table 2 ELISA analysis of testosterone and growth hormone levels in blood serum of Hanwoo beef cattles

\begin{tabular}{lcccc}
\hline \multicolumn{1}{c}{ Treatments } & $\begin{array}{c}\text { Early castrated } \\
(n=6)\end{array}$ & $\begin{array}{c}\text { Late castrated } \\
(n=8)\end{array}$ & $\begin{array}{c}\text { Non-castrated } \\
(n=10)\end{array}$ & $\begin{array}{c}\text { Female } \\
(n=4)\end{array}$ \\
$\begin{array}{l}\text { Testosterone level in blood } \\
\text { serum }(\mathrm{ng} / \mathrm{ml})\end{array}$ & $0.22 \pm 0.07^{\mathrm{a}}$ & $0.42 \pm 0.20^{\mathrm{a}}$ & $20.71 \pm 5.85^{\mathrm{b}}$ & $0.24 \pm 0.02^{\mathrm{a}}$ \\
$\begin{array}{l}\text { Growth hormone level in } \\
\text { blood serum }(\mathrm{ng} / \mathrm{ml})\end{array}$ & $3.94 \pm 1.62^{\mathrm{a}}$ & $16.66 \pm 8.26^{\mathrm{b}}$ & $13.19 \pm 7.56^{\mathrm{a}, \mathrm{b}}$ & $4.91 \pm 1.15^{\mathrm{a}}$ \\
\hline
\end{tabular}

(A)

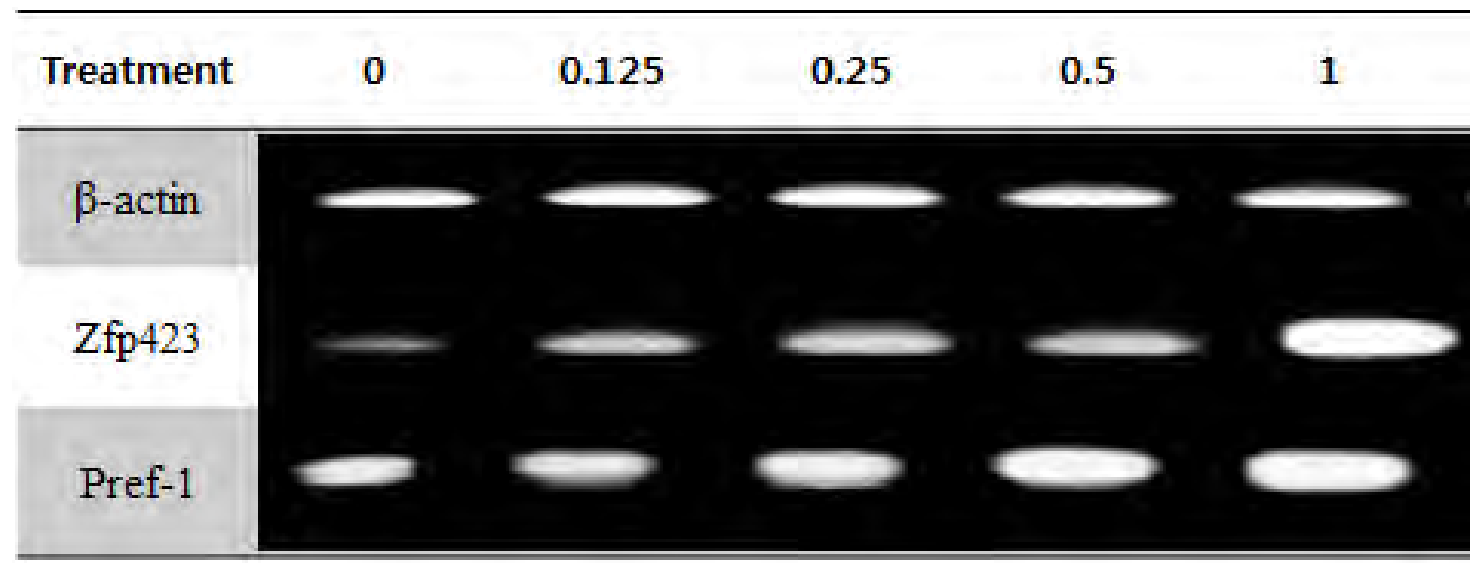

(B)

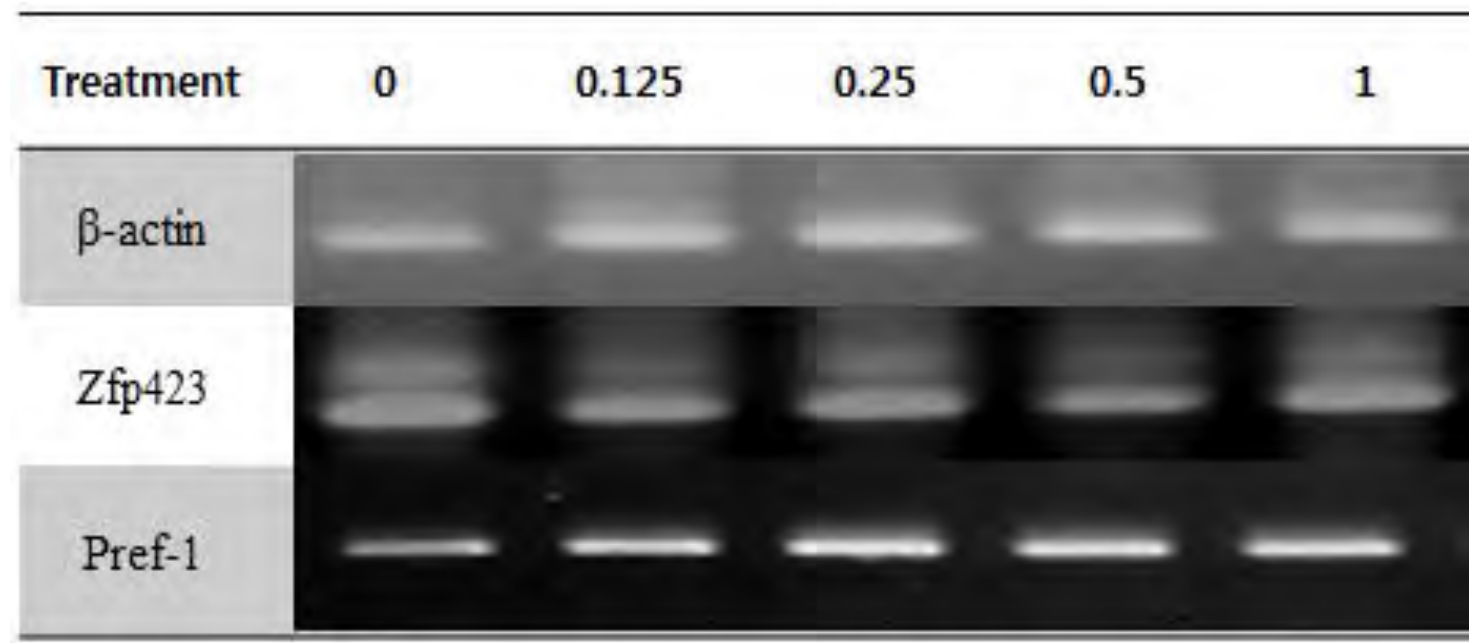

Figure 1 Representative mRNA bands of committed preadipocytes genes expressions, Zfp423 and Pref-1, in SVC isolated from Hanwoo beef cattle after $72 \mathrm{~h}$ treatments with different concentrations of (A) acetate and (B) propionate. 
(A)

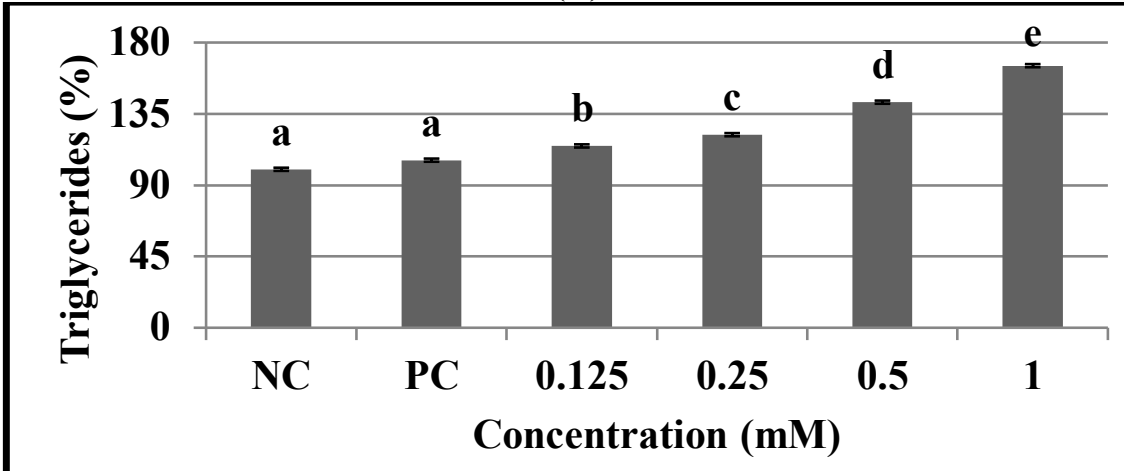

(B)

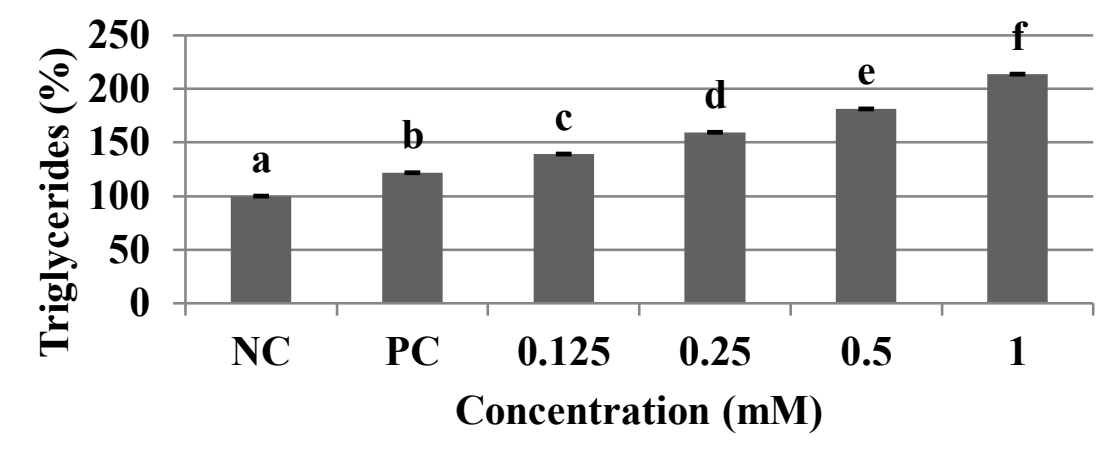

Figure 3 Effect of different levels of (A) acetate and (B) propionate on SVC differentiation after 14 days. The Oil-Red-O was washed with isopropanol and measured at $520 \mathrm{~nm}$. Data are means $\pm \mathrm{SE}$ of five replicate experiments. Bars with different superscripts are significantly different $(P<0.05)$.

(A)

\begin{tabular}{|c|c|c|c|c|c|}
\hline Treatment & o & 0.125 & 0.25 & 0.5 & 1 \\
\hline \multicolumn{6}{|l|}{$\beta$-actin } \\
\hline \multicolumn{6}{|l|}{$\operatorname{PPAR} \gamma$} \\
\hline \multicolumn{6}{|l|}{$\mathrm{C} / \mathrm{EBP} \alpha$} \\
\hline \multicolumn{6}{|l|}{ SREBP-1C } \\
\hline FABP4 & . & 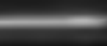 & & & \\
\hline
\end{tabular}

(B) 


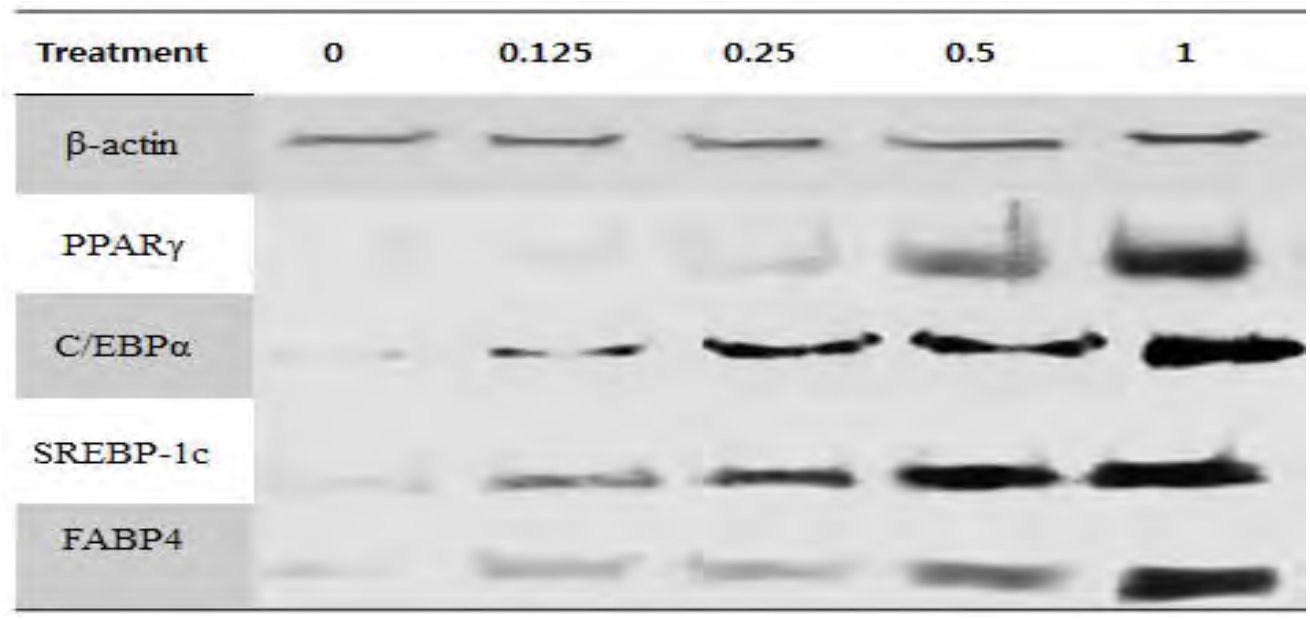

Figure 4 (A) Representative mRNA bands and (B) representative protein bands related with adipogenesis of fully differentiated SVC after treatment with different levels acetate.

(A)

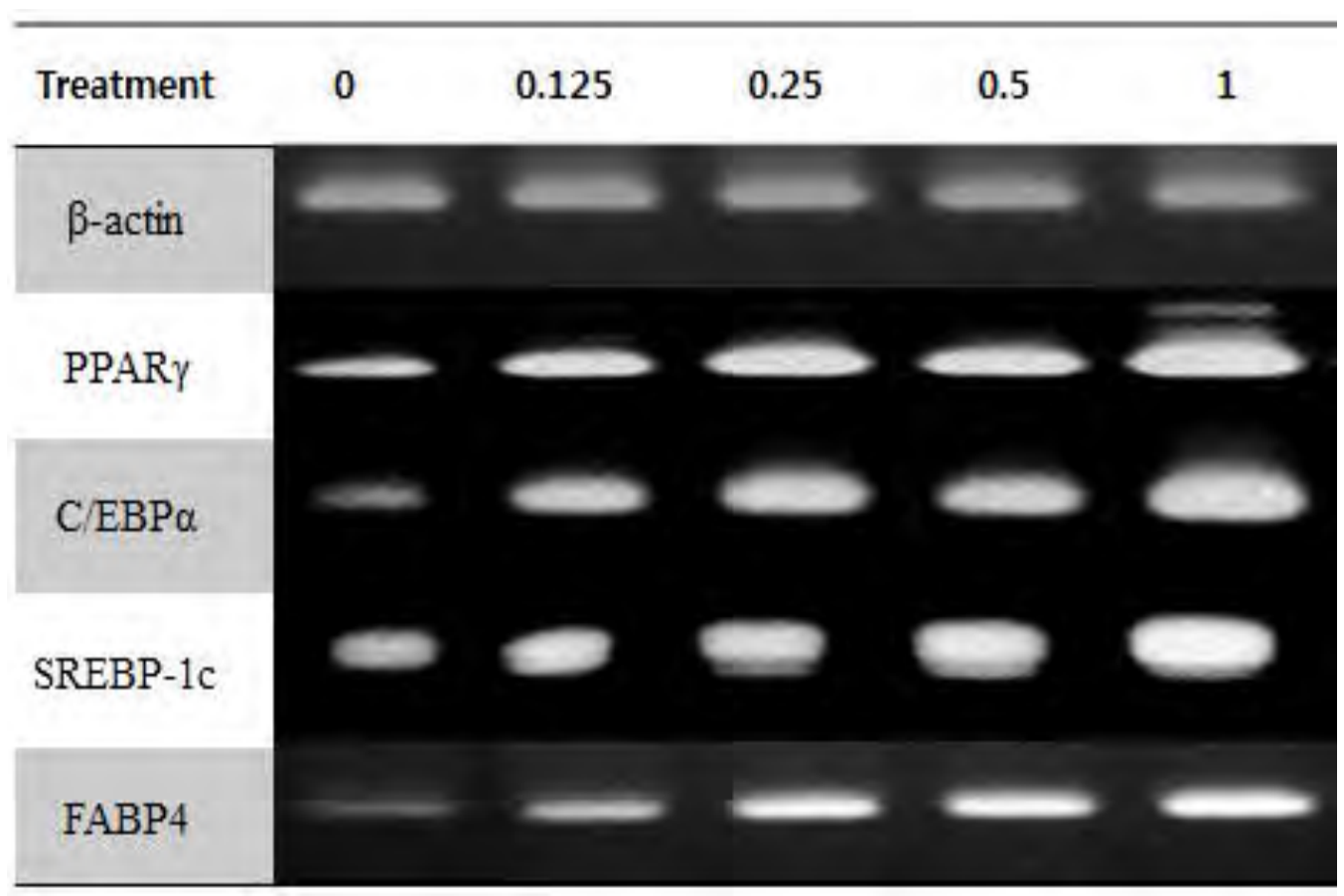

(B) 


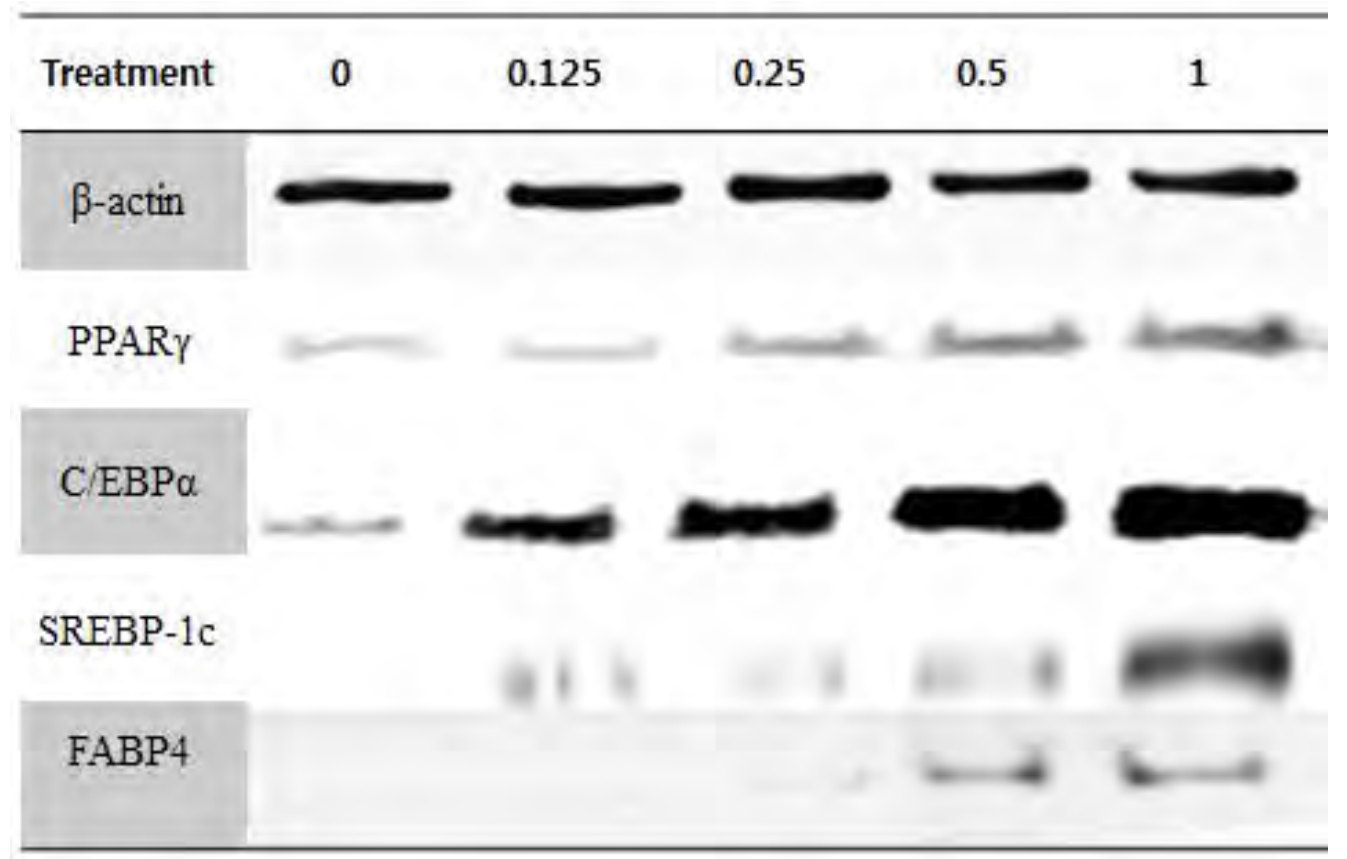

Figure 5 (A) Representative mRNA bands and (B) representative protein bands related with adipogenesis of fully differentiated SVC after treatment with different levels acetate. 
(A)

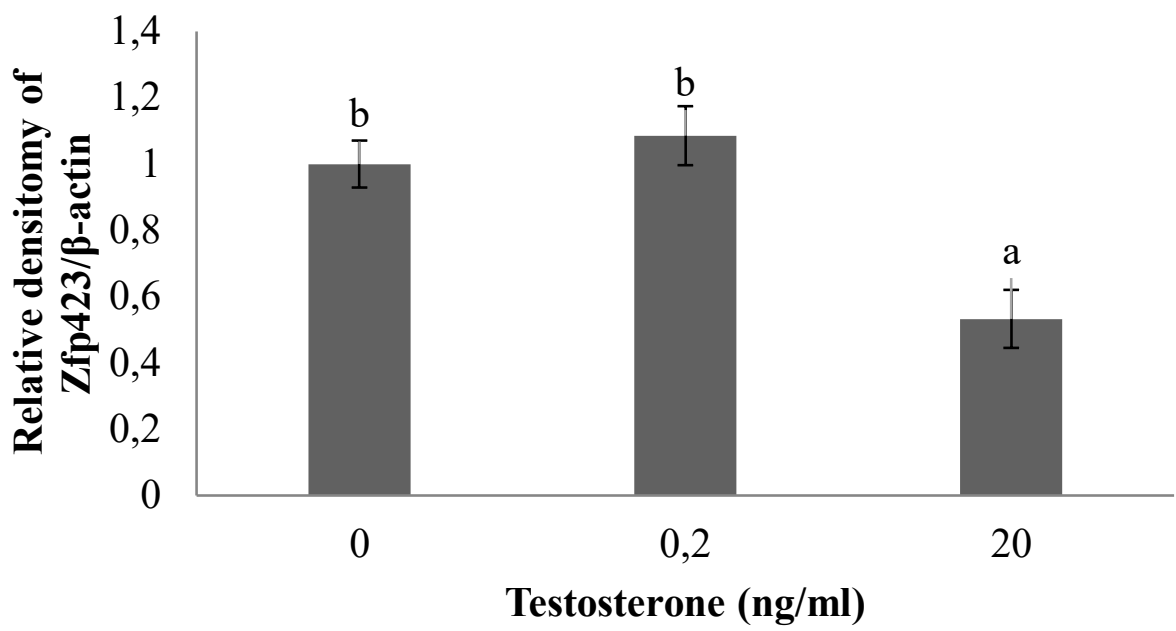

(B)

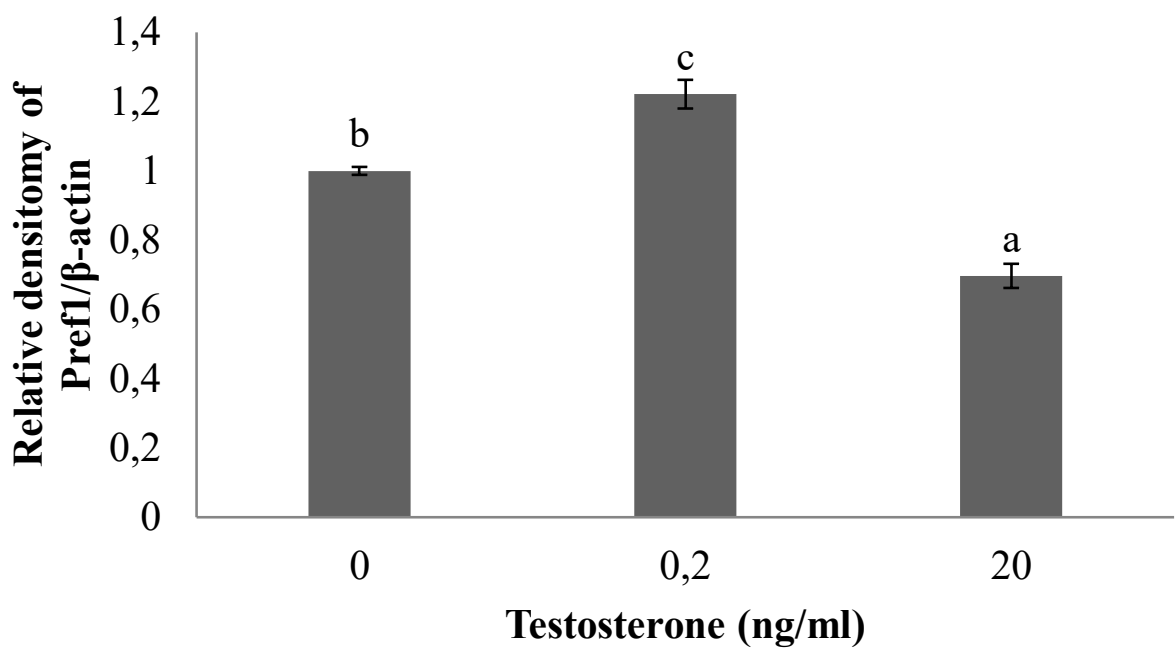

Figure 6 Effect of testosterone on preadipogenic genes expressions were quantified by Real-Time PCR using SYBR Green. Expressions of preadipogenic gene (A) Zfp432 and (B) Prefl were expressed as ratio of $\beta$-actin levels. The ratio of the normal group was set to 1.00. Data are means $\pm S E(n=3)$. Bars with different superscripts are significantly different $(p<0.05)$. 
(A)

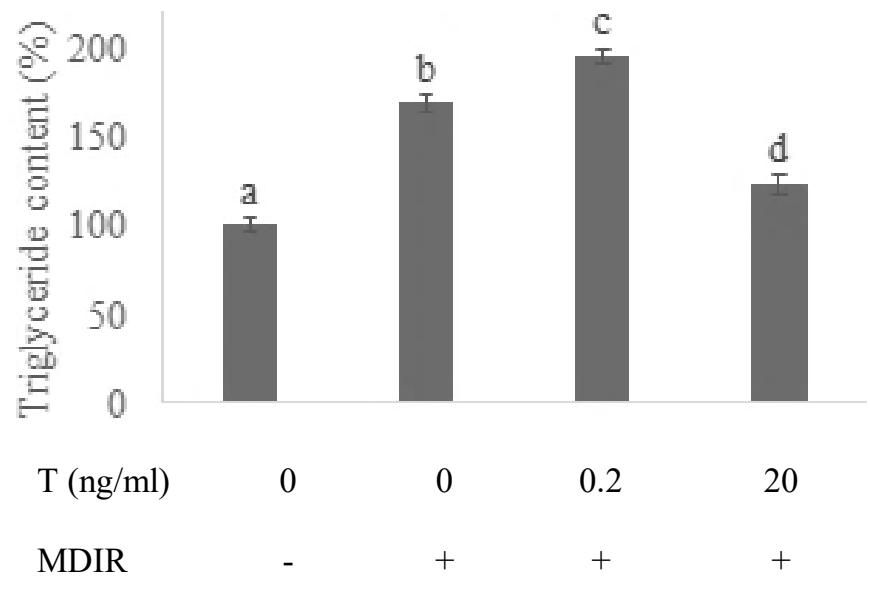

(B)

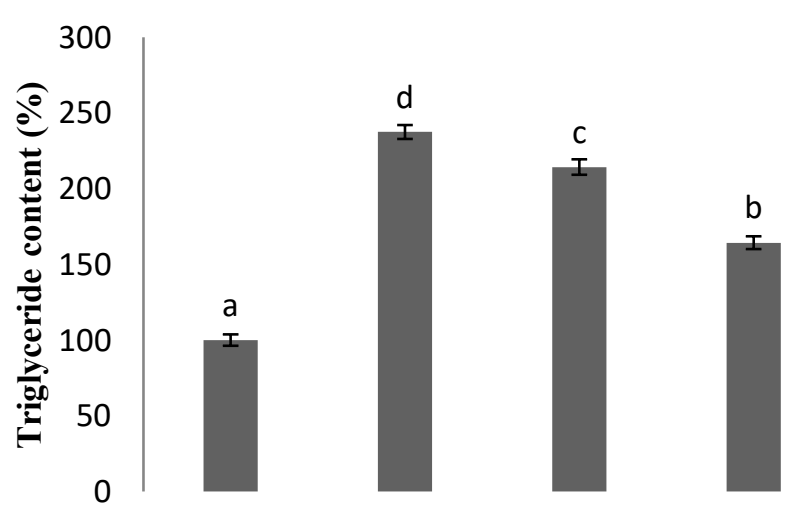

$\begin{array}{lcccc}\mathrm{GH}(\mathrm{ng} / \mathrm{ml}) & 0 & 0 & 5 & 15 \\ \text { MDIR } & - & + & + & +\end{array}$

Figure 7 Effect of different levels of (A) testosterone and (B) growth hormone on SVC differentiation after 14 days. The OilRed-O was washed with isopropanol and measured at $520 \mathrm{~nm}$. Data are means $\pm \mathrm{SE}$ of five replicate experiments. Bars with different superscripts are significantly different $(P<0.05)$. 
(A)
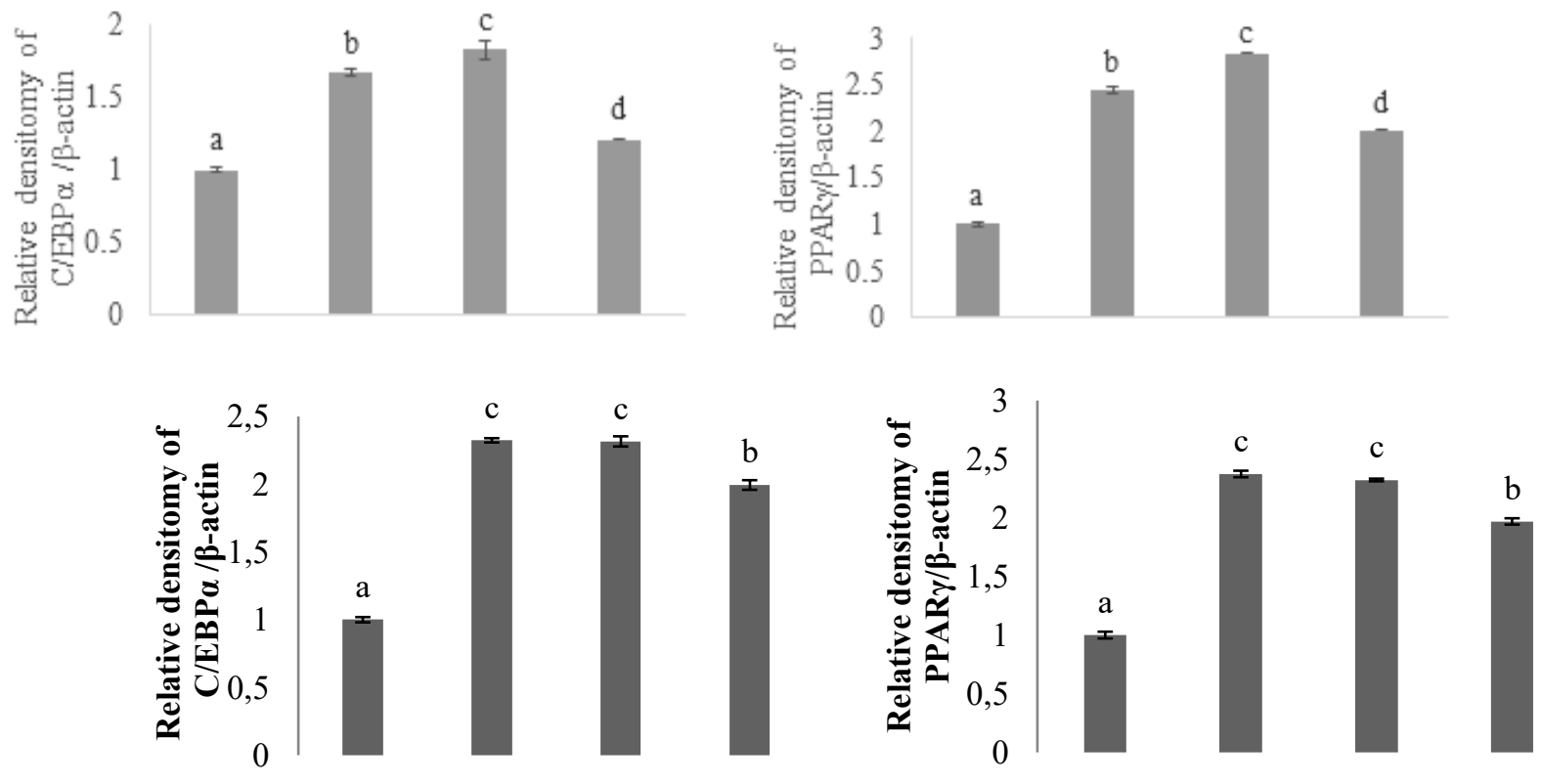

$\begin{array}{llllllllll}\mathrm{GH}(\mathrm{ng} / \mathrm{ml}) & 0 & 0 & 5 & 15 & \mathrm{GH}(\mathrm{ng} / \mathrm{ml}) & 0 & 0 & 5 & 15 \\ \mathrm{MDIR} & - & + & + & + & \text { MDIR } & - & + & + & +\end{array}$

Figure 8 Effect of (A) testosterone and (B) growth hormone early adipogenic genes expression after 14 days. mRNA expressions were quantified by Real-Time PCR using SYBR Green. C/EBP $\alpha$ and PPAR $\gamma$ were expressed as ratio of $\beta$-actin levels. The ratio of the normal group was set to 1.00. Data are means $\pm S E(n=3)$. Bars with different superscripts are significantly different $(\mathrm{p}<0.05)$. 